\title{
Certificação ISO 9001 em uma instituição pública de ensino e pesquisa agrícola: um
}

\section{estudo de caso}

\author{
ISO 9001 certification in a public institution for education and agricultural research: a case study \\ Certificación ISO 9001 en una institución pública de enseñanza e investigación agropecuaria: un
} estudio de caso

Recebido: 20/01/2022 | Revisado: 29/01/2022 | Aceito: 05/02/2022 | Publicado: 07/02/2022

Sérgio Vieira

ORCID: https://orcid.org/0000-0003-3468-161X Universidade Federal Rural do Rio de Janeiro, Brasil E-mail: ngssergio@gmail.com

Evandro Silva Pereira Costa

ORCID: https://orcid.org/0000-0002-3960-5221 Universidade Federal Rural do Rio de Janeiro, Brasil E-mail: evsilvacosta@gmail.com

Carlos Antônio dos Santos

ORCID: https://orcid.org/0000-0002-2840-2787 Universidade Federal Rural do Rio de Janeiro, Brasil E-mail: carlosantoniokds@gmail.com

Ricardo Luis Louro Berbara

ORCID: https://orcid.org/0000-0002-3649-9443 Universidade Federal Rural do Rio de Janeiro, Brasil E-mail: rberbara@gmail.com

\begin{abstract}
Resumo
Como forma de melhor atender as demandas de ensino e pesquisa voltadas ao desenvolvimento do setor agrícola, diferentes instituições públicas brasileiras têm investido na certificação de qualidade com a adoção da norma internacional ISO 9001. O objetivo deste trabalho foi analisar as condições existentes no Setor de Grandes Culturas (SGC) do Departamento de Fitotecnia da Universidade Federal Rural do Rio de Janeiro (UFRRJ), diagnosticar nãoconformidades perante a norma ISO 9001 e submeter os métodos elaborados à auditoria de primeira parte. Realizouse um levantamento das condições existentes nas instalações agropecuárias da instituição, com diagnóstico das nãoconformidades perante os requisitos da norma ISO 9001 e estabelecimento de método rastreável que permitisse atender aos requisitos normativos. Os métodos elaborados receberam certificação de conformidade do sistema de gestão de qualidade por meio da realização de auditoria de primeira parte. A certificação de qualidade no SGC poderá impulsionar o desenvolvimento de políticas institucionais centradas na renovação, qualificação contínua dos colaboradores, aumento da eficiência e sustentabilidade operacional, estreitamento de relações com instituições públicas e privadas, desenvolvimento de uma cultura sustentável e busca constante pela excelência na qualidade dos produtos e serviços prestados e oferecidos. As experiências reportadas nesse estudo poderão colaborar para o fomento à gestão da qualidade em outras instituições públicas e privadas voltadas à atividade agrícola.

Palavras-chave: Certificação de qualidade; Gestão integrada; Pesquisa agrícola; Agronegócio; Políticas institucionais.

Abstract

Many Brazilian public institutions have invested in quality certification with the adoption of the international standard ISO 9001 to meet research and educational demands focused on the development of the agricultural sector. This work aims to analyze existing conditions in the Crop Sector (SGC) of the Plant Science Department of the Universidade Federal Rural do Rio de Janeiro (UFRRJ) and diagnose non-conformities with ISO 9001 standard as well as submit developed methods to the first-party audit. The existent conditions at the agricultural facilities were assessed, therefore diagnosing non-conformities accordingly to ISO 9001 standard requirements and, as a result, establishing a traceable method that complies with the normative requirements. Certification of conformity from the quality management system was granted to the developed methods by a first-party audit. As a conclusion we can say that the certification of SGC may advance the development of future institutional policies focused on renewal, continuous qualification of staff, increased efficiency and operational sustainability, closer relations with public and private institutions, development of a sustainable culture, and constant pursuit for excellence in the quality of products and services provided. The experiences reported in this study may collaborate to promote quality management in other public institutions focused on agricultural activity.
\end{abstract}

Keywords: Quality certification; Integrated management; Agricultural research; Agribusiness; Institutional policies. 


\section{Resumen}

Como una forma de satisfacer mejor las demandas de enseñanza e investigación dirigidas al desarrollo del sector agrícola, diferentes instituciones públicas brasileñas han invertido en la certificación de calidad con la adopción de la norma internacional ISO 9001. El objetivo de este trabajo fue analizar las condiciones existentes en el Sector de Grandes Cultivos (SGC) del Departamento de Fitotecnia de la Universidad Federal Rural de Rio de Janeiro (UFRRJ), diagnosticar las no conformidades con la norma ISO 9001 y presentar los métodos desarrollados interna. Se realizó un levantamiento de las condiciones existentes en las instalaciones agrícolas de la institución, con un diagnóstico de las no conformidades a los requisitos de la norma ISO 9001 y establecimiento de un método de trazabilidad que permita cumplir con los requisitos normativos. Los métodos desarrollados recibieron la certificación de cumplimiento del sistema de gestión de calidad a través de una auditoría interna. La certificación de calidad en el SGC puede impulsar el desarrollo de políticas institucionales enfocadas en la renovación, calificación continua de los empleados, aumento de la eficiencia y sostenibilidad operativa, el acercamiento a las instituciones públicas y privadas, desarrollo de una cultura de sostenibilidad y búsqueda constante de la excelencia en la calidad de los productos y servicios prestados. Las experiencias reportadas en este estudio pueden contribuir a la promoción de la gestión de la calidad en otras instituciones públicas y privadas dedicadas a la actividad agropecuaria.
\end{abstract}

Palabras clave: Certificación de calidad; Gestión integrada; Investigación agropecuaria; Agronegocios; Políticas institucionales.

\title{
1. Introdução
}

Diferentes instituições públicas de ensino e pesquisa voltadas a atividades agrícolas têm investido em sistemas de certificação na busca constante pela excelência em seus produtos e serviços. Este comportamento representa, portanto, uma tendência de busca por qualidade no setor público (Marin, 2012; Mendes \& Crippa, 2013; Vitiello et al., 2016). Diferentes normas internacionais que avaliam qualidade podem ser aplicadas a instituições públicas e, dentre estas, destaca-se a norma ISO 9001 (ABNT, 2015). Ela regulamenta o sistema de gestão da qualidade, tendo como base a aplicação e gestão de uma série de processos que visam tanto aumentar a produtividade e a satisfação dos clientes, como supervisionar as atividades dentro da organização. A norma ISO 9001 é um padrão certificável de qualidade que foca principalmente na obtenção de processos eficazes e clientes satisfeitos (Maekawa et al., 2013). No entanto, é necessário considerar que a maioria dos estudos envolvendo a norma ISO 9001 é feita em organizações privadas, como os trabalhos feitos por Soares (2014) e Oliveira et al. (2020). Poucos estudos abordam estas experiências no setor público, notavelmente em instituições de ensino e pesquisa (Wittmann, 2011).

As instituições de pesquisa e desenvolvimento e demais organizações públicas, de uma maneira geral, têm se deparado com demandas diversas que apontam para o redirecionamento de suas ações diante das novas exigências impostas pelo mercado (Morais, 2008). Portanto, é um consenso que a certificação por meio de normativas como a ISO 9001 tenderá a ser um pré-requisito para todas as instituições de pesquisa em nível mundial (Mendes \& Crippa, 2013). No Brasil, é possível exemplificar o caso da Embrapa Meio Ambiente (Mendes et al., 2008; Mendes \& Crippa, 2013) e do Instituto Biológico de São Paulo (Vitiello et al., 2016) como precursoras da adoção a esta norma em organizações públicas e com atividades relacionadas à agricultura. Este comportamento representa, segundo Marin (2012), uma saudável e bem-vinda tendência de busca por qualidade no setor público.

Morais (2008) aponta que muitas dessas instituições, com uma cultura tecnológica consolidada, fruto de toda uma experiência e vivências individuais e coletivas adquiridas, podem apresentar ao longo do tempo disfunções e deformações. Dentre as quais, ressalta-se a perda de qualidade, baixa produtividade, desperdícios, desmotivação e custos elevados, carecendo de um direcionamento cultural sinérgico voltado para a excelência da qualidade (Morais, 2008). Diante disso, conforme explorado por Santos et al. (2014), a normatização é utilizada cada vez mais pelas instituições como um elemento para se alcançar a redução de custos de seus processos, produtos e serviços, além de sustentar a melhoria contínua da qualidade de seu sistema de gestão.

A implantação de um sistema de gestão da qualidade em uma instituição pública é um processo que pode ser lento e 
trabalhoso e que envolve uma série de modificações. Estas podem variar desde a adequação da infraestrutura das instalações, aquisição, calibração e verificação de equipamentos, até a capacitação de funcionários, qualificação de fornecedores de insumos e serviços, o monitoramento, entre outras etapas que são importantes para se assegurar um serviço ou produto de qualidade (Vitiello et al., 2016).

Para a implementação da norma ISO 9001 é necessária a realização de auditorias visando a identificação de pontos fracos ou pontos com possibilidades de melhorias. A auditoria de primeira parte ou auditoria interna, é realizada pela própria organização, com o objetivo de uma autoavaliação do sistema de gestão da qualidade. A auditoria de segunda parte, que é realizada por um cliente, tem o objetivo de avaliar a organização e qualificá-la de acordo com os critérios próprios do mesmo. Já a auditoria de terceira parte ou externa, é realizada por um organismo certificador e visa à obtenção da certificação na norma ISO ou outra norma certificável (Schmitt Júnior, 2014).

O objetivo deste trabalho foi realizar um levantamento das condições existentes nas instalações do Setor de Grandes Culturas (SGC) do Departamento de Fitotecnia da Universidade Federal Rural do Rio de Janeiro (UFRRJ), diagnosticar nãoconformidades perante os requisitos da norma ISO 9001 e submeter os métodos elaborados à auditoria de primeira parte para obtenção de certificação do sistema de gestão. Pretende-se, com esta iniciativa, fomentar o futuro desenvolvimento de políticas institucionais voltadas ao aprimoramento da qualidade dos serviços e produtos oferecidos pela instituição, e fomentar a adoção da certificação de qualidade em organizações agrícolas.

\section{Metodologia}

No presente trabalho, utilizou-se como modelo de estudo de caso as instalações do Setor de Grandes Culturas (SGC) do Departamento de Fitotecnia da Universidade Federal Rural do Rio de Janeiro, localizada em Seropédica, no Estado do Rio

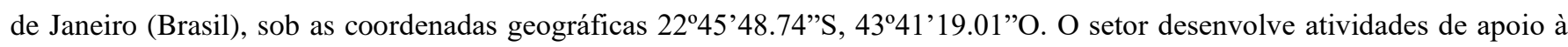
pesquisa e ensino agrícola, contando com área experimental de campo, áreas com cultivo protegido e laboratórios (UFRRJ, 2013; UFRRJ, 2021). A escolha do SGC como modelo de estudo fundamentou-se por ser um setor de campo inserido em uma universidade centenária e voltada à área de agricultura, que é um dos grandes pilares da economia brasileira. A escolha também foi pautada na escassez de pesquisas e de iniciativas relacionadas à gestão da qualidade em setores de campo em instituições públicas e de base agrícola.

Inicialmente, realizou-se a explanação teórica relacionada à certificação ISO 9001 em instituições de ensino e pesquisa com atividades voltadas à área agrícola. Detalhou-se, ainda, características gerais relacionadas ao setor objeto do estudo de caso, o SGC. Em seguida, foram discutidos aspectos levantados referentes ao setor. Coletaram-se dados de suas instalações, descrição e análise das atividades realizadas, assim como a padronização de procedimentos dos colaboradores do ponto de vista da qualidade, segurança, meio ambiente e aspectos sociais. Levantou-se informações sobre à organização espacial e funcional da instalação, assim como os conjuntos de plantas e também de novas propostas de layout para atender a norma ISO 9001 (ABNT, 2015). Realizou-se a capacitação de colaborador responsável pelo setor quanto ao Sistema de Gestão Integrado (SGI) (Moraes et al., 2013). Estabeleceram-se os diagnósticos e objetivos frente ao SGI, com a elaboração dos padrões gerenciais e de execução aplicáveis ao SGI da instalação em estudo. Ainda, direcionou-se à candidatura do sistema de gestão da instalação em estudo à certificação por meio de auditoria de primeira parte.

A partir das informações levantadas no SGC, análise documental da instituição, busca bibliográfica e discussão com os colaboradores do setor, foi proposta uma matriz SWOT contendo as forças e fraquezas, no ambiente interno, e suas oportunidades e ameaças, no ambiente externo (Leite \& Gasparotto, 2018).

Os dados obtidos no estudo foram discutidos por meio de uma abordagem teórica envolvendo os potenciais benefícios ao crescimento institucional, possíveis dificuldades durante o processo de certificação e oportunidades futuras relacionadas à 
implantação da norma ISO 9001 (ABNT, 2015) no setor estudado.

\section{Resultados e Discussão}

\subsection{Certificação ISO 9001 em instituições públicas de ensino e pesquisa agrícola}

ISO 9001 é a principal norma que compõe o sistema de gestão da qualidade estabelecido como modelo pela ISO, e tem por finalidade a certificação de sistemas de qualidade segundo seus requisitos específicos. Carpinetti et al. (2002) relatam a respeito da importância para uma organização em identificar, implantar, gerenciar e promover melhorias contínuas na eficácia dos processos necessários para o sistema de gestão da qualidade, além de gerenciar as interações desses processos para atingir seus objetivos. Muitos são os relatos da adoção de sistema de gestão da qualidade em empresas privadas. No setor público, estas iniciativas ainda são escassas (Wittmann, 2011), principalmente nas instituições voltadas à atividade agrícola (Mendes \& Crippa, 2013), como é o caso do SGC.

Dentre os exemplos atualmente disponíveis, é possível citar o caso da Embrapa Meio Ambiente que obteve em 2005 a certificação ISO 9001. Esta foi a primeira unidade da Embrapa a possuir esse certificado internacional. Ele reconhece a adoção de um sistema de gestão da qualidade que abrange todos os processos da unidade (Mendes et al., 2008; Mendes \& Crippa, 2013). Foram identificados problemas relacionados, principalmente, a atividade-fim, mais especificamente aqueles relacionados ao funcionamento dos laboratórios e campos experimentais. Segundo os autores, dentre os principais resultados oriundos da certificação pode-se exemplificar a reestruturação e readequação dos laboratórios da unidade; calibração de equipamentos e instrumentos de medição e ensaios; evolução no desempenho institucional e infraestrutura da unidade, aumento da capacitação e melhoria nas competências dos empregados e melhoria no clima organizacional e na motivação da comunidade interna.

Em 2007, com vista à tendência mundial para produtos certificados, a alta direção do Instituto Biológico de São Paulo (IB) buscou colaboradores internos para a implantação do sistema de qualidade baseado na ISO 9001. Para isso, elencou algumas unidades estratégicas para iniciar o processo de certificação, com o intuito de agregar novos departamentos gradativamente (Vitiello et al., 2016). Esta iniciativa foi de suma importância para a instituição, que desenvolve um grande número de programas de pesquisa científica em parceria com instituições nacionais e internacionais com vistas a atender o setor produtivo nas diferentes áreas de atuação, como o agronegócio.

Um estudo feito por Lopes (2015) aferiu as motivações que resultaram na decisão de avançar para um processo de certificação ao abrigo da Norma ISO 9001 no Setor de Recursos Humanos da Universidade do Minho, em Portugal. Neste, foi possível elencar um vasto conjunto de vantagens resultantes do processo. Dentre estas, os autores ressaltam maior eficiência organizacional (maior organização, melhoria do funcionamento, planejamento mais rigoroso e monitorizado, gestão e controle documental, melhoria dos tempos de resposta, maior controle da atividade e melhoria contínua, aumento de competências, maior produtividade, maior responsabilidade e maior orientação para a qualidade), melhoria da imagem, maior visibilidade e reconhecimento.

Outras experiências pontuais apontam iniciativas de certificação em andamento, como no caso da Coleção de Culturas de Microbiologia Agrícola da Universidade Federal de Lavras (CCMA-UFLA). Ao longo dos últimos 16 anos em funções, a CCMA-UFLA atua como uma infraestrutura universitária com a missão de aceitar depósitos, preservar e fornecer linhagens de microrganismos, bem como as informações associadas para fins de pesquisa e ensino em microbiologia agrícola e áreas afins (Universidade Federal de Lavras [UFLA], 2015). A CCMA-UFLA iniciou o processo de requalificação do seu acervo de microrganismos visando a implementação do sistema de gestão da qualidade (SGQ) baseado na ISO 9001 . Este processo tem sido desenvolvido em articulação com a Micoteca da Universidade do Minho (MUM), que é uma coleção de fungos filamentosos de referência internacional, já certificada por este referencial normativo (Pinto et al., 2014). 
3.2 Setor de Grandes Culturas do Departamento de Fitotecnia da Universidade Federal Rural do Rio de Janeiro

O SGC tem como visão de futuro consolidar-se como instituição de referência em pesquisa de campo para obtenção de material vegetal, integrando as ações de ensino, pesquisa e extensão na área agronômica, com ênfase na disseminação da cultura inovadora e em consonância com as demandas da sociedade brasileira (UFRRJ, 2013; UFRRJ, 2021).

O perfil de negócio adotado no SGC é a atividade-fim. O setor tem como finalidade atender às demandas de pesquisas científicas em condições de campo realizadas por professores e alunos de graduação e pós-graduação do Departamento de Fitotecnia da UFRRJ. Dentre as atividades realizadas inclui-se a obtenção de material vegetal, cujo objetivo é medir, quantificar e analisar os materiais produzidos em diferentes ensaios conduzidos nas instalações do Setor (Figura 1). No período de condução do estudo, a grande maioria dos trabalhos realizados no SGC estava relacionada à adaptação de cultivares às condições edafoclimáticas da região, sendo desenvolvidas pesquisas em diferentes áreas como sistemas agroflorestais, plantio orgânico, plantio convencional com uso de adubos químicos e agrotóxicos, e plantio em casa de vegetação (Figura 1). As principais culturas cultivadas no SGC são: arroz, feijão, milho, soja, aipim, amendoim, café, cacau, leguminosas arbustivas e arbóreas, plantadas em condições de campo ou em casa-de-vegetação.

Os clientes diretos do SGC são os alunos (de graduação, mestrado e doutorado) e professores que utilizam o setor para realização de suas pesquisas em condições de campo ou em casa-de-vegetação, bem como para a realização de aulas práticas. Já os clientes indiretos são os demais membros da comunidade acadêmica da UFRRJ e as agências de fomento que fornecem recursos financeiros para dar sustentação às pesquisas. As partes interessadas identificadas no escopo deste estudo foram: alunos, docentes, servidores, patrocinadores e fornecedores. Como provedores externos (patrocinadores) - listam-se atualmente as agências de apoio e fomento à pesquisa científica. Como fornecedores, listam-se os fornecedores de insumos (ferramentas, adubos químicos, etc), fornecedores de equipamentos e prestadores de serviços de manutenção.

O produto final alvo do sistema de gestão da qualidade no setor é o relatório da própria pesquisa científica resultante das análises e atividades. Tal produto apresenta níveis de complexidade diferenciados e pode se tornar um trabalho de disciplina, uma monografia, uma tese de mestrado ou de doutorado, ou ainda, um artigo. Aplicações e soluções voltadas ao desenvolvimento da agricultura também são esperadas. 
Figura 1. Detalhamento das atividades desenvolvidas no Setor de Grandes Culturas do Departamento de Fitotecnia da Universidade Federal Rural do Rio de Janeiro (SGC).

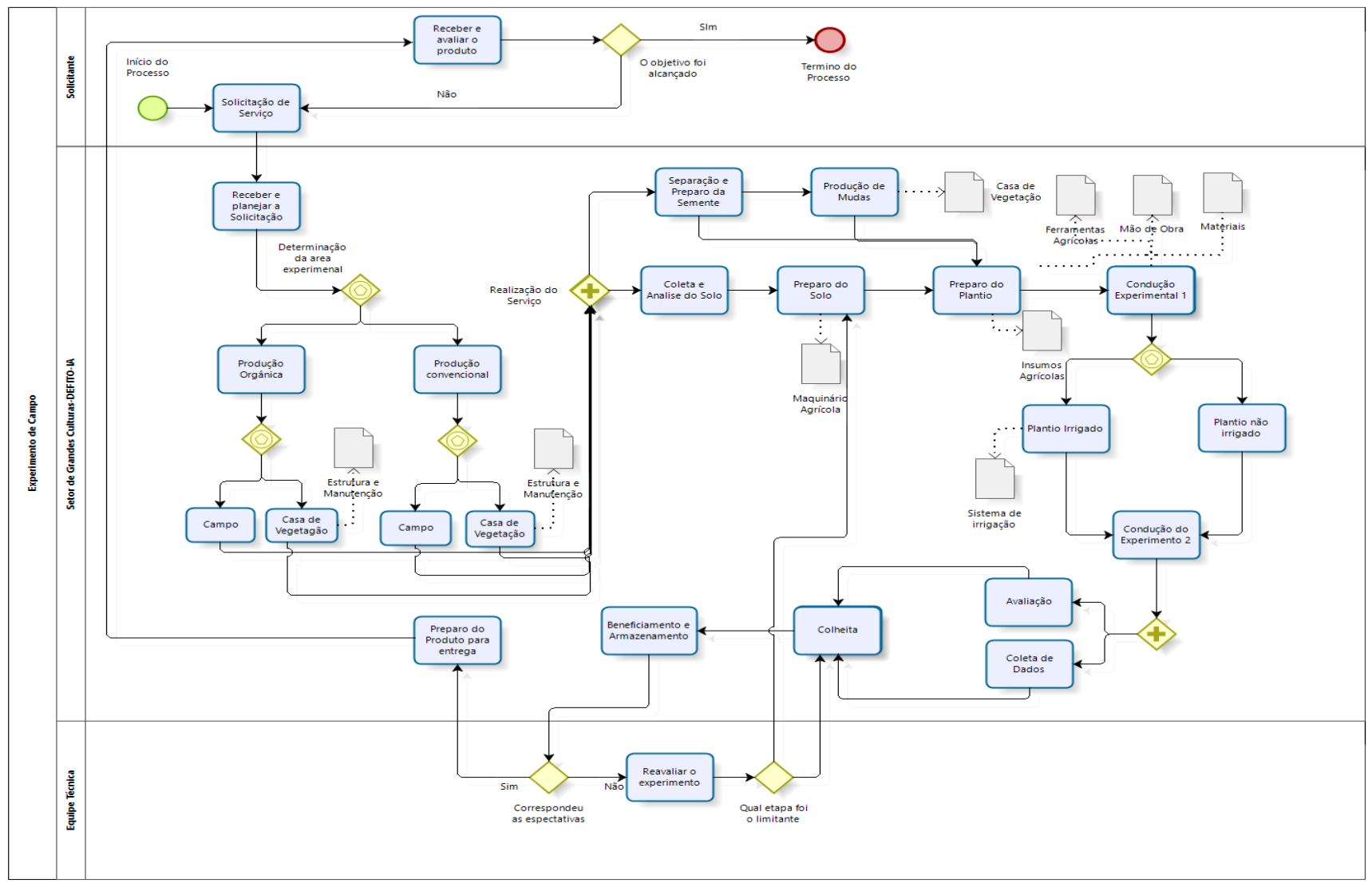

Fonte: Elaborado pelos autores.

\subsection{Diagnóstico das condições encontradas}

O SGC não apresentava um SGI estruturado e consolidado, ou qualquer iniciativa relacionada anteriormente à realização do presente trabalho. Portanto, os resultados obtidos referem-se ao estudo detalhado das condições encontradas nas instalações e ambientes de trabalho. Estes resultados foram estabelecidos como os padrões gerenciais e de execução, desenvolvidos para atender a análise de diagnósticos realizados, necessários ao atendimento dos requisitos estabelecidos pela norma ISO 9001.

As condições iniciais observadas no SGC apresentavam pontos que comprometiam a gestão e qualidade das atividades desenvolvidas. Observou-se que não havia nenhum tipo de contato com os clientes para o fornecimento de feedbacks, baixo controle e organização de documentos e dados específicos do setor ou controle de registros e, ainda, nenhuma inspeção nem identificação de equipamentos. Observaram-se também lacunas quanto à comunicação institucional e deficiências no tocante à infraestrutura de trabalho e nas relações com os provedores externos. O número de funcionários do SGC era reduzido e a equipe apresentava-se desmotivada e sem recebimento de nenhum tipo de treinamento. Havia também uma grande lacuna quanto à padronização das atividades de manuseio, armazenamento, embalagem, preservação e entrega dos produtos e serviços aos clientes.

A partir do treinamento e capacitação técnica do responsável pelo SGC em curso de formação de auditores de sistemas de gestão da qualidade (SGQ) e modelo de excelência de gestão (MEG), foram elaborados os padrões gerenciais e de execução. Estes padrões foram elaborados visando a correção das deficiências anteriormente mencionadas e atendimento aos requisitos apresentados pela norma ISO 9001. Como forma de entender o sistema de gestão de qualidade proposto, seus 
processos e contexto, elaborou-se a Figura 2 contendo os macroprocessos integrados e a sequência e interação desses processos (Figura 2).

Figura 2. Macroprocessos integrados contendo os processos executados pelo Setor de Grandes Culturas (SGC) do Departamento de Fitotecnia da Universidade Federal Rural do Rio de Janeiro, com a sequência e interação desses processos.

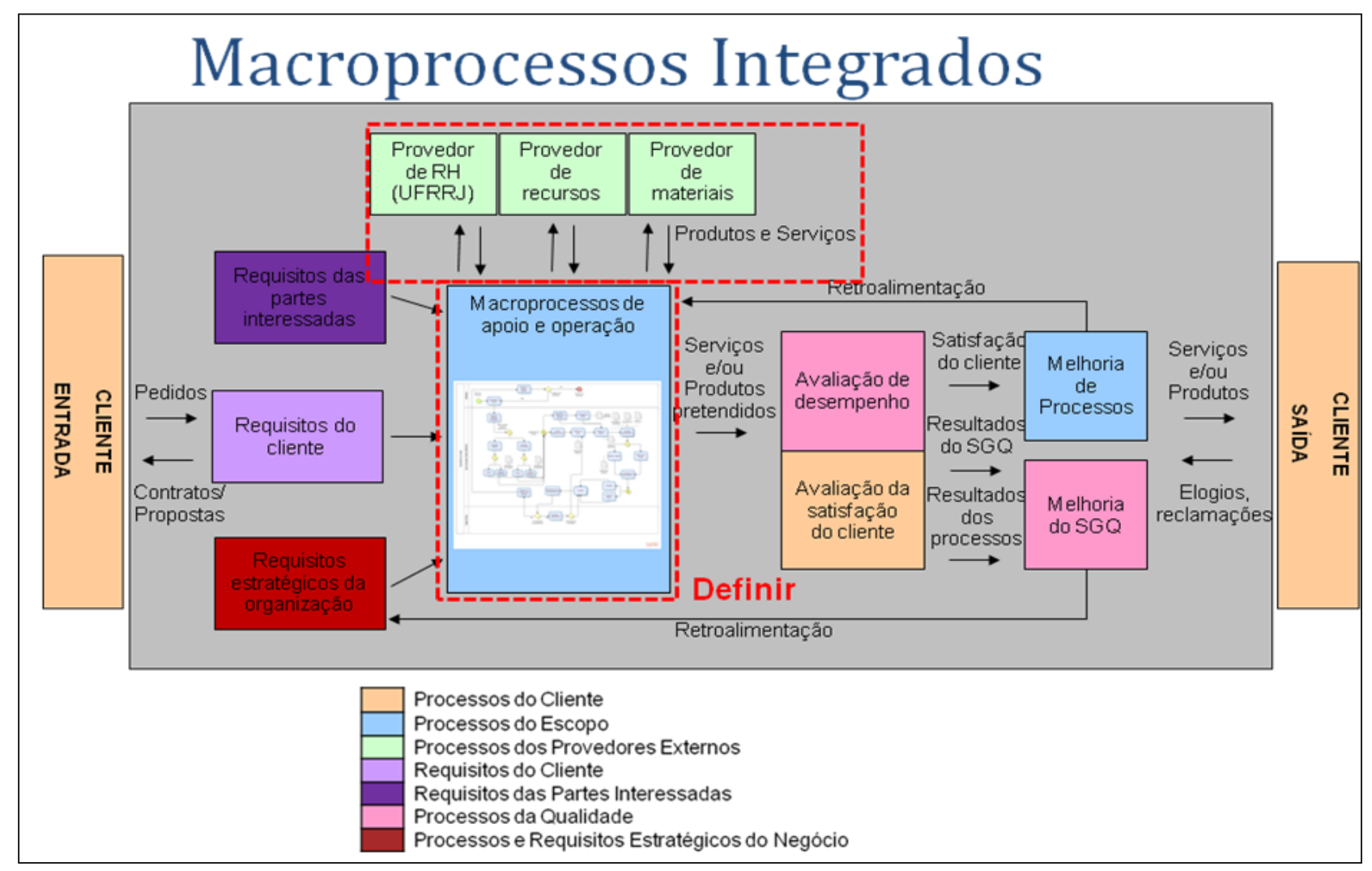

Fonte: Elaborado pelos autores.

Conforme o percentual de requisitos atendidos pelos métodos elaborados em relação à norma ISO 9001, candidatouse a instalação em estudo à certificação de conformidade do sistema de gestão por meio da realização de auditoria de primeira parte. O relatório de auditoria interna reportou que os métodos elaborados não apresentavam nenhuma não-conformidade, porém indicavam oito itens com oportunidade de melhoria. Dentre estes itens, ressaltam-se: inclusão no plano operacional de ação ou programas a metodologia do uso da área experimental para acompanhamento de histórico de uso, inclusão de número nas solicitações de serviços como forma de registro e melhor controle do processo, além de outras melhorias pontuais.

A validação se deu na obtenção do percentual de métodos elaborados que atendem aos requisitos obrigatórios da norma ISO 9001, conforme documentos de auditoria e certificação de conformidade do sistema de gestão. O SGC recebeu certificado de conformidade de seu sistema de gestão na categoria Prata (Assessoria de Gestão da Qualidade - COPPEQ/UFRJ), com base nos métodos elaborados.

Foi proposta uma matriz SWOT contendo as forças e fraquezas no ambiente interno, e suas oportunidades e ameaças no ambiente externo (Leite \& Gasparotto, 2018). As forças são fatores internos positivos que a instituição tem total controle. Estes fatores devem ser explorados ao máximo para que a mesma se mantenha com um bom posicionamento em seu segmento de atuação e diminua suas fraquezas (Silva et al., 2011). No caso do SGC, podem ser listadas como suas principais forças ou pontos fortes a tradição e solidez da instituição na área de atuação; equipe de colaboradores com experiência e diferentes expertises; disponibilidade de espaço e estrutura para realização de atividades de pesquisa e ensino e parcerias estabelecidas com outras instituições. Já os pontos fracos ou fraquezas são características ou deficiências internas, atuais ou potenciais, que 
prejudicam ou dificultam, substancialmente, e por longo tempo, o cumprimento da missão e/ou objetivos estratégicos da instituição (Marcelino, 2004). Pode-se listar, no caso do SGC, dificuldades políticas e trocas de gestão institucional; descontinuidade de projetos por parte da instituição; falta de orientação estratégica e investimentos financeiros oscilantes.

As oportunidades e ameaças são os resultados da análise ambiental externa, enquanto que as forças e fraquezas correspondem ao resultado de análise do ambiente interno (Fuscaldi \& Marcelino, 2008; Fernandes, 2012; Leite \& Gasparotto, 2018). No caso do SGC, as principais oportunidades são o estreitamento de relações público-público e público-privada, com injeção de recursos e investimentos, treinamentos, e expectativa de crescimento da economia e da agricultura, o que impulsiona as atividades desenvolvidas no setor. Já como ameaças, podem ser listadas as mudanças no cenário governamental com impacto nas instituições públicas e de fomento, burocracia, corte nos investimentos públicos e queda na economia brasileira.

A adesão do SGC e da UFRRJ à sistemas de gestão de qualidade projeta perspectivas de benefícios diversos, assim como os anteriormente mencionados referentes às experiências de outras intuições públicas de ensino e pesquisa. Dentre estes, destacam-se melhorias quanto ao atendimento do público e conquista da confiança desse público que, no caso do SGC, é formado majoritariamente por estudantes e professores da universidade; facilidade na identificação de prioridades e estratégias; melhoria contínua na gestão dos processos; alocação mais eficiente dos recursos e redução dos custos; gestão baseada em fatos; maior valorização, capacitação, reconhecimento e satisfação dos servidores; gerenciamento eficaz da informação e comunicação aberta com os gestores; fortalecimento da comunicação; e agilidade quanto à tomada de decisão.

No entanto, é importante considerar que não há somente fatores positivos no processo de implementação de programas da qualidade no setor público. Pires e Macedo (2006), por exemplo, apontam alguns traços específicos da organização pública que dificultam a adoção de ferramentas como esta. Os autores citam como fatores negativos o burocratismo, a interferência política externa à organização, apego às regras e rotinas e a descontinuidade da gestão (Pires \& Macedo, 2006). Com isso, apesar dos potenciais benefícios, a implementação e emprego futuro da normatização ISO no SGG poderá apresentar impeditivos que deverão ser superados coletivamente. Um destes desafios é o encontro de uma cultura organizacional já estabelecida e com resistência por parte dos profissionais envolvidos. Pode ser listado, ainda, a falta de recursos financeiros por parte da instituição visando a adequação das atividades do setor às normas, pouco envolvimento da gestão administrativa para o incentivo da implementação, dificuldades quanto à burocracia envolvida, e experiência da instituição neste segmento.

No SGC, as atividades são voltadas à área agrícola e executadas por funcionários com distintas atribuições e graus de escolaridade. Neste setor, é possível destacar grupos como trabalhadores de campo e de suporte a laboratórios, tratoristas e operadores de máquinas, e que possuem pouca ou média escolaridade; enquanto outro grupo é formado por técnicos agrícolas e engenheiros-agrônomos, muitos dos quais com qualificação em nível de doutorado, e que desempenham funções de suporte, coordenação ou chefia. A utilização da normatização ISO poderá trazer mudanças na dinâmica e rotina das atividades desenvolvidas no SGC, podendo ser vista como receio por parte dos funcionários. A resistência dos funcionários em todos os níveis hierárquicos devido a uma cultura organizacional fortemente sedimentada é, de forma geral, um consenso entre as diferentes instituições que visam a implementação de sistemas de melhorias na qualidade (Depexe \& Paladini, 2007). Esta percepção, no entanto, poderá variar de acordo com a forma com que estas informações são apresentadas e das contrapartidas oferecidas durante o processo.

De forma geral, as mudanças, através da adoção de uma nova metodologia de trabalho, tecnologia ou tipo de comportamento, desagradam aos colaboradores, uma vez que estes sentem que o seu espaço está ameaçado e desta forma tendem naturalmente a resistir a elas. Para isso, é necessário mostrar a maneira mais eficiente de realizar os serviços e explicar as consequências negativas das falhas, tanto para a instituição como para o colaborador. Desta forma, há maior valorização e 
integração dos trabalhadores, que entendem fazer parte de uma causa única (Depexe \& Paladini, 2007).

Em levantamento realizado por Maekawa et al. (2013) que tratou da implantação da ISO 9001 no Brasil, foi observado que a resistência dos funcionários consistiu na dificuldade encontrada de forma mais expressiva nas situações analisadas. No entanto, vale ressaltar que um dos maiores benefícios reportados no mesmo estudo foi a maior conscientização dos empregados em relação à qualidade, ou seja, uma vez vencida a resistência dos funcionários, esse aspecto se converte em benefício para a organização. Outros autores como Silva Júnior (2013) ao analisar a implementação ISO 9001 em uma série de empresas, encontraram como principais dificuldades a disseminação da cultura da qualidade, falta de comprometimento de toda a organização e a resistência dos colaboradores.

Apesar da burocracia envolvida e das dificuldades previstas, a certificação do SGC quanto à norma ISO 9001 poderá contribuir para a melhoria das atividades desenvolvidas no setor e, em uma visão mais ampla, projeta benefícios estendíveis a toda a instituição. Com isso, aceitar o desafio de que a mudança nem sempre rompe modelos, mas pode fazer modelos operarem com qualidade, ajuda a reduzir a insegurança que muitas vezes impede a adesão aos sistemas de gestão de qualidade em instituições públicas (Fowler et al., 2011), como o proposto neste presente estudo de caso.

A UFRRJ, por ser uma instituição pública com atividades de ensino, pesquisa e extensão, apresenta em seu quadro de docentes profissionais extremamente qualificados e com expertise em diferentes áreas e subáreas do conhecimento, como a agricultura, foco principal das atividades do SGC, e também em áreas complementares, como administração, contabilidade, recursos ambientais, gestão de pessoas, gestão de resíduos, tecnologias e outras. Com a certificação da qualidade, estes profissionais poderão ter a oportunidade de renovar suas habilidades e construir novas ferramentas e ações em conjunto, angariando benefícios e resultados à instituição como um todo.

Com a melhor estruturação, organização e aumento da eficiência dos setores da universidade, poderão ser potencializadas as interações com outras instituições e empresas, fomentando parcerias público-público e público-privada, que promoverão a injeção de recursos para a promoção do desenvolvimento sustentável da UFRRJ. Aliado a isso, a implementação de um sistema de gestão de qualidade servirá como um modelo didático de referência aos alunos tendo em vista o papel da instituição na formação de profissionais qualificados.

Ao ser considerado o ciclo PDCA (Planejar, fazer, checar e agir), observa-se que o processo de certificação do SGC quanto à norma ISO 9001, foram concluídas a etapa inicial de planejamento, e apenas iniciadas às atividades vinculadas aos processos de fazer, checar e agir. Isto é, foi realizado o treinamento de colaborador responsável pelo setor em estudo, identificados os principais problemas e ações corretivas a serem realizadas, e estabelecidos os planos de ação. Será necessário, ainda, a implementação destes planos de ação, o que exigirá esforços e investimentos dos colaboradores e da instituição, conforme anteriormente discutido.

Neste trabalho, foram estabelecidos os padrões gerenciais e de execução, contextualizados às condições encontradas nas instalações e ambientes de trabalho do SGC. Estes foram desenvolvidos para atender a análise de diagnósticos realizados, necessários ao atendimento dos requisitos estabelecidos pela norma ISO 9001 (Sistema de Gestão da Qualidade - SGQ), e posteriormente, a obtenção de certificação dos métodos elaborados por meio de auditoria de avaliação dos métodos desenvolvidos.

A certificação de implementação dos métodos elaborados não consistiu no objetivo deste estudo de caso, que abordou apenas o processo de auditoria de primeira parte, em virtude dos prazos estabelecidos e por depender do investimento de recursos financeiros e humanos da instituição. Segundo Schmitt Júnior (2014) a auditoria interna deve ser encarada como uma preparação para uma auditoria de segunda ou terceira parte, onde pode-se obter informações importantes da organização e agir para correção de problemas identificados ou gerar melhorias para o sistema. Com isso, a continuidade das etapas de certificação do SGC deve ser encorajada e exigirá esforços coletivos entre os colaboradores do SGC e a gestão da instituição. 
A auditoria externa, ou auditoria de terceira parte, é realizada por um auditor independente (designado pelo órgão certificador credenciado pelo INMETRO) para fins de certificação do sistema de gestão do qual a empresa deseja. A auditoria externa analisa se o sistema de gestão de uma organização foi estabelecido, documentado e mantido de acordo com uma norma específica, sendo, portanto, a fase final do processo de certificação (Verde Ghaia, 2020).

É esperado, portanto, que o SGC seja certificado com brevidade. A certificação perante a norma ISO 9001 de um setor de campo inserido em uma universidade pública federal, centenária, e de base agrícola, será um marco para o aprimoramento da qualidade em instituições de serviço público no Brasil. A partir disso, será possível que o SGC se consolide como uma instituição de referência em pesquisa de campo para obtenção de material vegetal, integrando as ações de ensino, pesquisa e extensão, com ênfase na disseminação da cultura inovadora e em consonância com as atuais demandas da sociedade.

\section{Considerações Finais}

O emprego da normatização ISO no SGC facilitará o entendimento da capacidade de suporte e de pontos e situações que atingiram ou estarão próximas de atingirem seus limiares. Com base nos resultados reportados por outras instituições públicas de ensino e pesquisa que desenvolvem atividades correlatas às do SGC e anteriormente discutidos, é esperado, com a certificação, que o setor adote uma reestruturação e readequação dos seus laboratórios e áreas experimentais de campo; apresente melhorias quanto ao desempenho institucional e infraestrutura; aumente a eficiência quanto ao uso de insumos, agroquímicos e reagentes; reduza a sua produção de resíduos; aumente a eficiência no uso de máquinas agrícolas; eleve a capacitação e competências dos colaboradores; e promova melhorias no clima organizacional e na motivação da comunidade interna. A certificação de implementação, deverá ser encorajada e exigirá esforços coletivos entre as partes envolvidas.

Pode-se inferir, portanto, que a certificação ISO 9001 do SGC será uma ferramenta impulsionadora para o desenvolvimento de futuras políticas institucionais centradas na renovação, inserção de valores, qualificação contínua dos colaboradores, aumento da eficiência e sustentabilidade operacional, estreitamento de relações entre instituições públicopúblico e público-privada, desenvolvimento de uma cultura sustentável entre as diferentes expertises que compõem a universidade, e busca constante pela excelência na qualidade dos serviços prestados ao desenvolvimento da agricultura brasileira.

\section{Referências}

ABNT - Associação Brasileira de Normas Técnicas. (2015). ABNT NBR ISO 9001:2015 Sistemas de gestão da qualidade. https://www.abntcatalogo.com.br/norma.aspx?ID=345041.

Carpinetti, L. C. R., Miguel, P. A. C. \& Gerolamo, M. C. (2010). Gestão da qualidade ISO 9001:2008: princípios e requisitos. Atlas.

Depexe, M. D., \& Paladini, E. P. (2007). Dificuldades relacionadas à implantação e certificação de sistemas de gestão da qualidade em empresas construtoras. Revista Gestão Industrial, 3(1), 13-25. 10.3895/S1808-04482007000100002

Fernandes, D. R. (2012). Uma visão sobre a análise da Matriz SWOT como ferramenta para elaboração da estratégia. Revista de Ciências Jurídicas e Empresariais, 13(2), 57-68. 10.17921/2448-2129.2012v13n2p\%25p

Fowler, E. D., Mello, C. H. P., \& Costa Neto, P. L. O. (2011). Análise exploratória da utilização do programa de qualidade GESPÚBLICA nas instituições federais de ensino superior. Gestão \& Produção, 18(4), 837-852. 10.1590/S0104-530X2011000400011

Fuscaldi, K. C., \& Marcelino, G. F. (2008). Análise SWOT: o caso da Secretaria de Política Agrícola. In Anais do XLVI Congresso da Sociedade Brasileira de Economia, Administração e Sociologia Rural, Rio Branco, AC. https://ideas.repec.org/p/ags/sbrfsr/110046.html Acesso em: 10/11/2021

Leite, M. S. R., \& Gasparotto, A. M. S. (2018). Análise SWOT e suas funcionalidades: o autoconhecimento da empresa e sua importância. Revista Interface Tecnológica, 15(2), 184-195. 10.31510/infa.v15i2.450

Lopes, M. J. F. (2015). Certificação ISO 9001 e Gestão de Recursos Humanos: precedentes e consequentes: estudo de caso das Unidades de Serviços Certificadas da Universidade do Minho (Tese de Doutorado). Universidade do Minho, Braga, Portugal. 
Maekawa, R., Carvalho, M. M., \& Oliveira, O. J. (2013). Um estudo sobre a certificação ISO 9001 no Brasil: mapeamento de motivações, benefícios e dificuldades. Gestão e Produção, 20(4), 763-779. 10.1590/S0104-530X2013005000003

Marcelino, G. F. (2004). Introdução ao planejamento e à administração estratégia. In G. F. Marcelino (Org.), Gestão estratégica em universidade: a construção da FACE-UnB (29-37). Brasília, UnB.

Marin, P. L. (2012). Sistemas de gestão da qualidade e certificação ISO 9001 na administração pública: uma análise crítica. In Anais do V Congresso Consad de Gestão Pública, Brasília, DF. https://bityli.com/CTgMx

Mendes, M. D. L., Sitton, M., Kitamura, P. C., \& Spadotto, C. A. (2008). A experiência da Embrapa Meio Ambiente como um modelo de gestão da qualidade para empresa pública. In Anais do Congresso da Associação Brasileira das Instituições de Pesquisa Tecnológica, Campina Grande, PB. https://bityli.com/hGuxm

Mendes, M. D. L. \& Crippa, M. E. N. (2013). Roteiro para Implantação de um Sistema de Gestão da Qualidade (SGQ) baseado na ISO 9001-Experiência da Embrapa Meio Ambiente. Jaguariúna, SP: Embrapa Meio Ambiente. https://bityli.com/Bggvm

Moraes, C. S. B., Vale, N. P., \& Araújo, J. A. (2013). Sistema de Gestão Integrado (SGI) e os benefícios para o setor siderúrgico. Revista Metropolitana de Sustentabilidade, 3(3), 29-48. http://revistaseletronicas.fmu.br/index.php/rms/article/view/214/pdf_1

Morais, J. D. (2008). Metodologia de implantação do sistema de gestão da qualidade NBR ISO 9001 : 2000 em instituições públicas de PD\&I (Tese de Doutorado). Universidade Federal da Paraíba, João Pessoa, Brasil.

Oliveira, P. F., Araújo Júnior, A. H., Barros, G. M., Sampaio, N. A. S., Nascimento, A. L. S., Barros, J. G. M., Silva, J. W. J, \& de Almeida, M. D. G. D. (2020). Estudo de atualização da norma ISO 9001 em uma empresa de bens de capital. Research, Society and Development, 9(10), e51985354, 2020. $10.33448 /$ rsd-v9i8.5354

Pinto, J., Gervasio, I., Dias, D., Eustáquio, D., Santos, C., Lima, N., \& Schwan, R. (2014). Coleção de culturas de microbiologia agrícola da UFLA (CCMAUFLA): da requalificação à certificação baseada na ISO 9001: 2008. In Congresso Brasileiro de Recursos Genéticos, Santos, SP. http://anais.infobibos.com.br/cbrg/Resumos/ResumoCBRG_423.pdf

Pires, J. C. S., \& Macedo, K. (2006). Cultura Organizacional em Organizações Públicas no Brasil. Revista de Administração Pública, 40(1), 81-105. $10.1590 /$ S0034-76122006000100005

Santos, A. R. S., Santos, L. D., Scalco, D., Servat, M. E., \& Polacinski, E. (2014). Sistema de gestão da qualidade: diretrizes para implementação da ISO 9001. In Anais da $4^{a}$ Semana Internacional de Engenharia e Economia, Horizontina, RS. https://bityli.com/wfWaO

Schmitt Junior, J. A. (2014). Auditoria interna do sistema de gestão da qualidade em indústrias: desafios básicos (Especialização em Gestão da Qualidade). Universidade Federal do Paraná, Curitiba, Brasil.

Silva Júnior, M. T. (2013). Benefícios e dificuldades na adoção de um sistema de gestão da qualidade no Rio Grande do Norte (Dissertação de Mestrado). Universidade Federal do Rio Grande do Norte, Natal, Brasil.

Silva, A. A., Silva, N. S., Barbosa, V. A., Henrique, M. R., \& Baptista, J. A. (2011). A utilização da matriz Swot como ferramenta estratégica-um estudo de caso em uma escola de idioma de São Paulo. In Anais do VIII Simpósio de Excelência em Gestão e Tecnologia, Resende, RJ. https://www.aedb.br/seget/arquivos/artigos11/26714255.pdf.

Soares, J. M. (2014). Estudo da relevância da norma ISO 9001 no desempenho das empresas portuguesas do sector da hotelaria. Tourism \& Management Studies, 10(2), 57-66. https://www.repository.utl.pt/bitstream/10400.5/4494/1/DM-CSRAL-2012.pdf

UFRRJ. (2021). Projeto Pedagógico. https://bityli.com/Kzaeq

UFRRJ. (2013). Plano de desenvolvimento institucional da UFRRJ - 2018-2022. https://portal.ufrrj.br/wp-content/uploads/2016/11/PDI-UFRRJ-20182022.pdf

Universidade Federal de Lavras (UFLA). (2015). Coleção de Culturas da Microbiologia Agrícola da UFLA ganha reconhecimento Internacional. Lavras, $M G$. https://bityli.com/xkUBL.

Verde Ghaia. (2020). Conheça os tipos de auditorias de sistema de gestão e para que servem. https://www.consultoriaiso.org/tipos-de-auditorias-sistema-degestao .

Vitiello, N., Miyshiro, S., Galleti, S. R., Vieira, M. S. V., Nascimento, E. S., \& Batista Filho, A. (2016). Sistema de gestão da qualidade no Instituto Biológico (SP): Relato da transição da NBR ISO 9001 para NBR ISO/IEC. Revista Gestão em Análise, 5(1), 7-17. 10.12662/2359-618xregea.v5i1.p7-17.2016

Wittmann, M. J. D. M. (2011). O impacto da certificação ISO 9001: sistema de gestão da qualidade na gestão de uma escola municipal de ensino fundamental (Doutorado em Educação). Universidade do Vale do Rio dos Sinos, São Leopoldo, Brasil. 